\title{
Propostas para o ensino e a pesquisa em cursos de graduação em instrumento musical: bases para uma reformulação do bacharelado
}

\author{
Proposals for Teaching And Research in Musical Instrument Undergraduate \\ Courses: Basis for a Review of The Bachelor Degree in Music Performance
}

\author{
Ricieri Carlini Zorzal \\ Universidade Federal do Maranhão, São Luís, Maranhão, Brasil. \\ ricieri@pq.cnpq.br
}

Resumo: Este trabalho traz uma reflexão sobre a realidade dos cursos de bacharelado em instrumento musical após a implementação das políticas do Programa de Apoio a Planos de Reestruturação e Expansão das Universidades Federais - Reuni. Assim, são discutidas propostas de reformulação dos referidos cursos a partir da valorização do ensino e da pesquisa na formação dos bacharelandos em música. Destarte, são apresentadas conceituações e aplicabilidades das estratégias de ensino de intrumento musical para a valorização do ensino, e são apresentadas abordagens qualiquantitativas para o estudo científico da aula de instrumento para a valorização da pesquisa na formação dos bacharelandos. Por fim, sugere-se a inclusão das disciplinas Pedagogia do Instrumento Musical e Pesquisa sobre o Ensino da Performance Musical na grade curricular dos bacharelados em instrumento musical para que estes cursos dialoguem com o contexto político-educacional vigente.

Palavras-chave: bacharelados em instrumento musical; Reuni; pesquisa em educação musical.

Abstract: This paper observes the undergraduate courses in music instrument from the point of view of the implementation of "Support Program for the Restructuring and Expansion of Federal Universities" - REUNI, which is a policy from Brazilian's government that has been implemented since 2007. In this sense, the appreciation of both education and research in undergraduate music training are discussed by means of quali-quantitative approaches to the scientific study of music performance lessons. Thus, this work elaborates concepts and applicability for the strategies employed during the teaching of musical instruments, presenting proposals for the development of new approaches for the performance and research on the bachelor's training. Finally, 
ZORZAL, Ricieri Carlini. (2016) Propostas para o ensino e a pesquisa em cursos de graduação em instrumento musical: bases para uma reformulação do bacharelado. Per Musi. Ed. por Fausto Borém, Eduardo Rosse e Débora Borburema. Belo Horizonte: UFMG, n.34, p.62-88.

there is a suggestion regarding the inclusion of two disciplines in bachelor degree's curricula in musical instrument, which are: "Pedagogy of Musical Instrument" and "Research on Musical Performance". With this, it is expected a dialogue between the undergraduate music courses with the current political and educational context.

Keywords: undergraduate courses in musical instrument; Reuni program in Brazil; research in music education.

Data de recebimento: 03/11/2015

Data de aprovação final: 19/03/2016

\section{1 - Situação atual dos bacharelados em música frente ao Reuni}

Passados sete anos da regulamentação do Programa de Apoio a Planos de Reestruturação e Expansão das Universidades Federais - Reuni, através do Decreto № 6.096/2007, percebe-se um considerável aumento na oferta de vagas de Música em nível superior. Das cinquenta e nove universidades federais atualmente existentes, 33 possuem o curso de música presencial em pelo menos uma das modalidades de licenciatura e bacharelado. A Figura 1 reflete essa realidade ${ }^{1}$ :

\begin{tabular}{|c|c|c|c|c|c|}
\hline & \multicolumn{2}{|c|}{ Licenciatura } & \multicolumn{2}{|c|}{ Bacharelado } & \multirow{2}{*}{$\begin{array}{l}\text { Quadro } \\
\text { docente }\end{array}$} \\
\hline & Habilitação & Vagas/ano & Habilitação & Vagas/ano & \\
\hline UFAC & Não especificada & 40 & $\mathrm{X}$ & $\mathrm{X}$ & 14 \\
\hline \multirow{2}{*}{ UFAL } & Instrumentos e Canto & \multirow{2}{*}{32} & \multirow{2}{*}{$\mathrm{X}$} & \multirow{2}{*}{$\mathrm{X}$} & \multirow{2}{*}{12} \\
\hline & Educação Musical & & & & \\
\hline UFAM & Não especificada & 52 & $\mathrm{X}$ & $\mathrm{X}$ & 17 \\
\hline \multirow{2}{*}{ UFBA } & \multirow{2}{*}{ Não especificada } & \multirow{2}{*}{16} & $\begin{array}{l}\text { Comp., Regência, } \\
\text { Instrumentos e Canto }\end{array}$ & 44 & \multirow{2}{*}{35} \\
\hline & & & Música Popular & 16 & \\
\hline $\mathrm{UFC}^{2}$ & Não especificada & 40 & $\mathrm{X}$ & $\mathrm{X}$ & 9 \\
\hline $\mathrm{UFC}^{3}$ & Educação Musical & 40 & $\mathrm{X}$ & $\mathrm{X}$ & 13 \\
\hline
\end{tabular}

${ }^{1}$ Consultas realizadas através do seguinte endereço eletrônico do Ministério da Educação (MEC): http://reuni.mec.gov.br/index.php?option=com_wrapper\&view=wrapper\&Itemid=29 e pelos sítios eletrônicos das universidades, com acesso aos projetos políticos pedagógicos dos respectivos cursos. Dados referentes a dezembro de 2014.

2 Campus Fortaleza.

${ }^{3}$ Campus Sobral. 
ZORZAL, Ricieri Carlini. (2016) Propostas para o ensino e a pesquisa em cursos de graduação em instrumento musical: bases para uma reformulação do bacharelado. Per Musi. Ed. por Fausto Borém, Eduardo Rosse e Débora Borburema. Belo Horizonte: UFMG, n.34, p.62-88.

\begin{tabular}{|c|c|c|c|c|c|}
\hline \multirow[t]{2}{*}{ UFCG } & \multirow[t]{2}{*}{ Não especificada } & \multirow[t]{2}{*}{30} & $\begin{array}{c}\text { Comp., Regência, } \\
\text { Instrumentos e Canto }\end{array}$ & \multirow[t]{2}{*}{10} & \multirow[t]{2}{*}{16} \\
\hline & & & Produção Musical & & \\
\hline UFES & Não especificada & 30 & Composição & 30 & 14 \\
\hline \multirow{2}{*}{ UFG } & Instrumentos e Canto & \multirow{2}{*}{38} & $\begin{array}{c}\text { Comp., Regência, } \\
\text { Instrumentos e Canto }\end{array}$ & 28 & \multirow{2}{*}{78} \\
\hline & Educação Musical & & Musicoterapia & 24 & \\
\hline UFJF & $\mathrm{X}$ & $\mathrm{X}$ & Instrumentos e Canto & 42 & 15 \\
\hline UFMA & Não especificada & 60 & $\mathrm{X}$ & $\mathrm{X}$ & 10 \\
\hline \multirow{3}{*}{ UFMG } & \multirow{3}{*}{ Educação Musical } & \multirow{3}{*}{30} & $\begin{array}{c}\text { Comp., Regência, } \\
\text { Instrumentos e Canto }\end{array}$ & 44 & \multirow{3}{*}{59} \\
\hline & & & Musicoterapia & 15 & \\
\hline & & & Música Popular & 15 & \\
\hline UFMT & Não especificada & 40 & $\begin{array}{l}\text { Comp., Regência, } \\
\text { Instrumentos e Canto }\end{array}$ & 24 & 20 \\
\hline UFOP & Instrumentos e Canto & 25 & $\mathrm{X}$ & $\mathrm{X}$ & 16 \\
\hline UFPA & Não especificada & 30 & $\mathrm{X}$ & $\mathrm{X}$ & 57 \\
\hline UFPB & Instrumentos e Canto & 60 & $\begin{array}{c}\text { Composição, } \\
\text { Instrumentos e Canto }\end{array}$ & 60 & 44 \\
\hline UFPE & Não especificada & 60 & Instrumentos e Canto & 20 & 26 \\
\hline \multirow{4}{*}{ UFPel } & \multirow{4}{*}{ Não especificada } & \multirow{4}{*}{30} & Instrumentos e Canto & 35 & \multirow{4}{*}{31} \\
\hline & & & Composição & 20 & \\
\hline & & & Música Popular & 20 & \\
\hline & & & Ciências Musicais & 10 & \\
\hline UFPI & Não especificada & 20 & $\mathrm{X}$ & $\mathrm{X}$ & 7 \\
\hline UFPR & Educação Musical & 20 & Produção Sonora & 20 & 13 \\
\hline \multirow[t]{2}{*}{ UFRGS } & \multirow{2}{*}{ Educação Musical } & \multirow[t]{2}{*}{-4} & $\begin{array}{c}\text { Comp., Regência, } \\
\text { Instrumentos e Canto }\end{array}$ & \multirow[t]{2}{*}{-} & \multirow[t]{2}{*}{34} \\
\hline & & & Música Popular & & \\
\hline UFRJ & Não especificada & 52 & $\begin{array}{c}\text { Comp., Regência, } \\
\text { Instrumentos e Canto }\end{array}$ & 104 & 90 \\
\hline UFRN & Não especificada & 40 & Instrumentos e Canto & 26 & 65 \\
\hline UFRR & Não especificada & 50 & $\mathrm{X}$ & $\mathrm{X}$ & 7 \\
\hline UFS & Educação Musical & 50 & $\mathrm{X}$ & $\mathrm{X}$ & 11 \\
\hline UFSCar & Educação Musical & 24 & $\mathrm{X}$ & $\mathrm{X}$ & \\
\hline \multirow{2}{*}{ UFSJ } & Instrumentos e Canto & 25 & \multirow{2}{*}{$\mathrm{X}$} & \multirow{2}{*}{$\mathrm{X}$} & \multirow{2}{*}{19} \\
\hline & Educação Musical & 15 & & & \\
\hline \multirow{2}{*}{ UFSM } & \multirow{2}{*}{ Não especificada } & 16 & Instrumentos e Canto & 35 & 29 \\
\hline & & 10 & Música e Tecnologia & 12 & 29 \\
\hline UFU & Instrumentos e Canto & 50 & Instrumentos e Canto & 50 & 27 \\
\hline UnB & Não especificada & 52 & $\begin{array}{c}\text { Comp., Regência, } \\
\text { Instrumentos e Canto }\end{array}$ & 52 & 37 \\
\hline UNILA & $\mathrm{X}$ & $\mathrm{X}$ & $\begin{array}{c}\text { Pesquisa em Música e } \\
\text { Práticas } \\
\text { interpretativas } \\
\end{array}$ & 25 & 12 \\
\hline $\begin{array}{c}\text { Uni } \\
\text { Pampa }\end{array}$ & Não especificada & 25 & $\mathrm{X}$ & $\mathrm{X}$ & 9 \\
\hline UNIR & Não especificada & 20 & $\mathrm{X}$ & $\mathrm{X}$ & 6 \\
\hline Unirio & Não especificada & 60 & $\begin{array}{c}\text { Comp., Regência, } \\
\text { Instrumentos e Canto }\end{array}$ & 63 & 57 \\
\hline & & & Música Popular & 20 & \\
\hline
\end{tabular}

${ }^{4}$ A UFRGS oferece, anualmente, 65 vagas que podem variar, conforme demanda e disponibilidade, entre os cursos de Licenciatura e Bacharelado. 
Figura 1: Panorama atual dos cursos de graduação em Música nas Universidades Brasileiras.

Os dados apresentados acima ainda não representam a totalidade do ensino superior de música no Brasil. Diversos estados da federação administram universidades que oferecem formação superior em música, e alguns institutos federais também passaram a proporcionar essa formação. Outrossim, é imprescindível destacar o surgimento de cursos de música a distância, tais como os da UFRGS, UFSCar e UnB55.

Pelo exposto, vê-se que o aumento e a diversificação das modalidades de graduação, matérias disciplinadas pelo susodito decreto, têm possibilitado a criação de cursos de bacharelado e licenciatura com habilitações em Música Popular, Musicoterapia, Educação Musical, Produção Musical e Ciências Musicais. CERQUEIRA (2013) destaca que trinta e cinco cursos de graduação em música foram criados nas universidades e institutos brasileiros desde 2006.

Além da criação de novos cursos, as diretrizes impostas pelo Decreto № 6.096/2007 têm impactado a rotina acadêmica dos cursos já existentes. A necessidade de redução das taxas de evasão, o aumento da ocupação das vagas ociosas, a ampliação das políticas de inclusão e a intensificação da mobilidade estudantil são alguns dos fatores que submetem os colegiados de curso a uma constante reflexão sobre estratégias a serem adotadas para atendimento deste mecanismo legal.

Nesse contexto de expansão e constante mudança, coloca-se a seguinte questão: o interesse do poder público pelos bacharelados em instrumento musical tem diminuído? A própria legislação indica que sim, pois há uma declarada preferência a não especialização precoce, e os bacharelados em instrumento não têm conseguido se adequar à situação atual. Para ratificar essa realidade, lembra-se que, dos trinta e cinco

\footnotetext{
${ }^{5}$ Uma discussão mais aprofundada sobre os contextos de criação e sobre a realidade vivida pelos cursos de música oferecidos pelos institutos federais e pelas universidades da região Nordeste é apresentado por ZORZAL e FERREIRA (2016).
} 
ZORZAL, Ricieri Carlini. (2016) Propostas para o ensino e a pesquisa em cursos de graduação em instrumento musical: bases para uma reformulação do bacharelado. Per Musi. Ed. por Fausto Borém, Eduardo Rosse e Débora Borburema. Belo Horizonte: UFMG, n.34, p.62-88.

novos cursos apontados por CERQUEIRA (2013), onze são na modalidade de bacharelado e apenas três desses bacharelados têm ênfase em instrumento musical. Embora seja manifesta a recente diminuição do interesse em bacharelados em instrumento musical, a tabela acima mostra que ainda é considerável tanto o número de vagas discentes oferecidas por esses cursos, quanto o quadro docente disponível para atender essa demanda.

Dessa forma, alguns autores se debruçam sobre os papéis do bacharelado em música e da performance musical nas universidades brasileiras. Por exemplo, TOURINHO e GURGEL (2013) estudam o mercado de trabalho para os egressos do bacharelado em violão. WEBER e GARBOSA (2014), em uma reflexão teórica sobre o "saber da performance" dos bacharéis que atuam como professores de instrumento musical, apontam para a necessidade de uma formação pedagógica no processo formativo desses profissionais. CERQUEIRA, ZORZAL e ÁVILA (2012) desenvolvem um modelo teórico para o ensino e aprendizagem da performance musical e SCARDUELLI e FIORINI (2013) propõem um programa de curso de bacharelado em violão que inclui na formação do estudante, além da performance, atividades de ensino e pesquisa. Vêse a ampliação dos conteúdos trabalhados nos cursos de bacharelado em instrumento musical como aspecto indispensável para que esses cursos se adequem ao atual contexto político.

As atividades de ensino propostas por SCARDUELI e FIORINI envolvem "experiência e conhecimentos da pedagogia do violão e seus métodos, a partir de projetos de monitoria e disciplinas que ofereçam aporte teórico na área" (SCARDUELI e FIORINI, 2013, p.221). Nesse sentido, esses autores sugerem que as disciplinas Pedagogia do Violão I e II façam parte da grade curricular do bacharelado em violão e propõem um conteúdo programático fortemente enfatizado tanto nos mais conhecidos métodos para o instrumento, quanto numa série de estudos para violão extraída do repertório de tradição ocidental. 
ZORZAL, Ricieri Carlini. (2016) Propostas para o ensino e a pesquisa em cursos de graduação em instrumento musical: bases para uma reformulação do bacharelado. Per Musi. Ed. por Fausto Borém, Eduardo Rosse e Débora Borburema. Belo Horizonte: UFMG, n.34, p.62-88.

Todavia, um grande entrave para as mudanças necessárias na gestão político pedagógica dos cursos de bacharelado em instrumento musical pode residir no legado conservatorial que esses cursos carregam. Sobre os aspectos apresentados por esse legado, pondera COUTO:

Tal modelo de ensino se baseia na relação mestre-aprendiz, aonde se defende a atenção exclusiva ao estudante como a única forma de poder conseguir um resultado efetivo. Falamos aqui de um modelo que é eficiente por um lado, pois lida de maneira profunda e personalizada com a aprendizagem, mas excludente por outro, na medida em que é oferecido a poucos escolhidos que foram capazes de alcançar aprovação em rígidos testes de seleção (COUTO, 2014, p.243).

PEREIRA (2014) chama de habitus conservatorial a reprodução dessa relação entre mestre e aprendiz. Entre as características do habitus conservatorial que este autor elenca, destacam-se:

- $\quad$ O individualismo no processo de ensino: princípio da aula individual com toda a progressão do conhecimento, técnica ou teórica, girando em torno da condição individual; a existência de um programa fixo de estudos, exercícios e peças (orientados do simples para o complexo) considerados de aprendizado obrigatório, estabelecidos como meta a ser alcançada;

- A música erudita ocidental como conhecimento oficial; a supremacia absoluta da música notada - abstração musical;

- A primazia da performance - prática instrumental/vocal (PEREIRA, 2014, p.93);

A discussão apresentada evidencia certa tensão entre a transmissão de uma herança musical e o áspero encargo do professor em proporcionar ao aluno uma autonomia em seu aprendizado. GAUNT (2008), que ocupa cargo de gestora em instituição de ensino de instrumentos musicais e estuda essa relação tutorial entre professor e aluno, aponta essa dicotomia. Em síntese, os bacharelados em instrumento devem vencer o "habitus conservatorial" e se diversificar com proposições "não voltadas à profissionalização precoce e especializada".

Dessa forma, o presente artigo traz uma reflexão teórico-conceitual sobre estratégias de ensino de instrumento musical e visa contribuir com o desenvolvimento dos eixos de ensino e pesquisa para os cursos de bacharelado em instrumento. Nesse sentido, são propostas categorizações e aplicabilidades para as estratégias de ensino discutidas 
na literatura especializada e são indicadas algumas possibilidades metodológicas para análise de dados para pesquisas na área. Frisa-se que a reflexão aqui proposta é parte do referencial teórico de uma pesquisa sobre estratégias de ensino de instrumento musical em masterclasses que tem sido conduzida pelo autor e conta com o apoio financeiro da FAPEMA e do CNPq6.

\section{2 - Reflexões sobre teorias e práticas no ensino de instrumento musical}

A prática de ensino do professor de instrumento musical é desenhada pelas estratégias utilizadas durante as aulas. Tais estratégias objetivam a compreensão holística do conhecimento musical a partir das performances apresentadas ao longo da preparação de um repertório. Dessa forma, o conhecimento musical, conforme as proposições de ELLIOTT (1995), pressupõe a capacidade de verbalização, reflexão e realização em música. Assim, o professor deve cumprir algumas metas no processo de acompanhamento de seus alunos: proporcionar a possibilidade de desenvolvimento do conhecimento formal sobre música, com noções que possam orientar suas ações; considerar e avaliar as escolhas técnicas e artísticas surgidas do conhecimento informal; proporcionar a capacidade de julgamento das opções interpretativas disponíveis; e desenvolver a capacidade de supervisionar seu próprio desenvolvimento musical, ou seja, desenvolver a consciência na utilização de estratégias metacognitivas (BARRY; HALLAM, 2002). Para tanto, o professor deve empregar eficazmente estratégias verbais e não verbais de ensino, além de fazer um uso consciente dos recursos computacionais e de mídia disponíveis.

O uso prático da linguagem figurada suscita a atenção de diversos pesquisadores (BARTEN, 1998; SKOOG, 2004; STOLLAK; ALEXANDER, 1998; WOODY, 2002; 2004). E

\footnotetext{
6 Os argumentos do item 2 da presente discussão, inclusos seus subitens, estão publicados com modificações em um capítulo de livro de autoria do mesmo autor deste artigo. Por este motivo, citações a este capítulo não foram individualmente referenciadas (ver ZORZAL, 2014).
} 
ZORZAL, Ricieri Carlini. (2016) Propostas para o ensino e a pesquisa em cursos de graduação em instrumento musical: bases para uma reformulação do bacharelado. Per Musi. Ed. por Fausto Borém, Eduardo Rosse e Débora Borburema. Belo Horizonte: UFMG, n.34, p.62-88.

isso ocorre por que a metáfora é tida como a mais popular e a mais comum das estratégias tradicionais de ensino da expressividade musical (LINDSTRON et al., 2003).

SWANWICK (2003) considera que a habilidade de realizar transformações metafóricas torna o estudante capaz de dar sentido às estruturas musicais e expressar-se musicalmente. Ou seja, propõe-se que a relação entre significante e significado é sempre metafórica e, por conseguinte, que o processo cognitivo confia no processo metafórico para mover-se ao entendimento (PHILPOTT, 2001). A partir dessa proposição, pode-se estabelecer que a metáfora cumpre seu papel de importante estratégia de ensino da expressividade musical, pois a metáfora pode relacionar "o mundo subjetivo do performer aos aspectos objetivos da performance" (JUSLIN; PERSSON, 2002, p.227).

Embora seja útil como meio de verbalização da expressão musical, algumas considerações devem ser feitas sobre o uso da linguagem metafórica (PERSSON, 1996; SHELDON, 2004). SCHIPPERS (2006) considera três tipos de metáforas no ensino de música: o clichê; a metáfora criativa; e a referência obscura. Clichê é uma metáfora tão familiar que não é capaz de proporcionar um aprendizado significativo. A metáfora criativa evoca a dissonância cognitiva, a qual pode ser resolvida pela aplicação de uma ampla estrutura de referência pelo aluno. A referência obscura também cria a dissonância cognitiva, mas não permite que essa dissonância seja solucionada pelo aluno. Professores de instrumento devem estar conscientes que o uso da metáfora no ensino de música precisa ser contextualizado e sua primordial função é estabelecer relações entre um novo estímulo e a experiência do estudante, caso contrário toda a elaboração pode tornar-se irrelevante para uma situação de aprendizagem eficiente (WOODY, 2004).

A verbalização em aulas de música pode assumir, além da linguagem metafórica, formas como a modelagem, a instrução usando a terminologia musical, e outros tipos de linguagem figurada. Analogias, similaridades e imagens verbais são consideradas outras importantes formas da linguagem figurada (SHELDON, 2004). 
A atenção dada à linguagem figurada em aulas de música pode ser ratificada ou complementada pelo uso da linguagem literal de acordo com as características de cada situação. Ao analisar a linguagem verbal empregada em aulas de canto e diversos instrumentos musicais em um conservatório, BURWELL (2006) identifica diferenças claras no conteúdo e na forma dessas aulas. De acordo com este autor, as aulas ministradas aos cantores abordam mais questões técnicas que questões expressivas. Os cantores, quando comparados aos instrumentistas em geral, recebem também mais instruções por meio da linguagem metafórica que por meio da linguagem literal. 0 intensivo uso de imagens e metáforas em aulas de canto, inclusive no ensaio de coros, é corroborado por STOLLAK e ALEXANDER (1998).

Não obstante, as estratégias de ensino de música têm sido vistas como complementares. WOODY (2001; 2002) utiliza três categorias para o uso da linguagem figurada no ensino da expressividade musical: relacionada ao humor; relacionada ao movimento fora do contexto musical; e relacionada ao movimento de natureza musical. Nessas pesquisas, o autor solicita aos professores de instrumento que elaborem instruções de performance expressiva com o uso da linguagem figurada com a mesma qualidade das seguintes estratégias: instrução de propriedades musicais concretas; modelagem aural não verbal; e imitação. Essa qualidade similar entre as estratégias é garantida por juízes independentes. 0 autor conclui que as três categorias da linguagem figurada são complementares no ensino da expressividade musical.

Em outro estudo, dessa vez com trinta e seis estudantes de piano, WOODY (2006) encontra que modelagem aural, instrução verbal de propriedades musicais concretas e instrução verbal com o uso de imagens e metáforas são abordagens complementares de ensino para a obtenção de expressividade na performance musical, cada uma com seus pontos fortes e pontos fracos. Sob a ótica dos ouvintes, a expressão musical também pode ser verbalizada com consistência, tanto utilizando a terminologia musical concreta quanto fazendo uso da linguagem figurada (SHELDON, 2004). 
A forma como a linguagem verbal é empregada pelos professores de música também tem sido estudada. DUKE e HENNINGER (1998) investigam cinquenta estudantes em aulas individuais de performance musical sob duas diferentes condições. Na primeira condição os alunos receberam apenas estratégias verbais de ensino que utilizavam o feedback negativo, e na segunda receberam aulas com a linguagem verbal utilizada como instrução corretiva direcionada na performance. Essa pesquisa mostra que a condição experimental, onde os alunos receberam apenas o feedback negativo, não afetou suas atitudes positivas sobre a experiência das aulas e nem a realização da performance obtida. Outro resultado dessa pesquisa mostra que o tempo de estudo necessário para se atingir as metas e as qualidade final da performance alcançada por esses alunos não foram diferentes entre os grupos experimental e controle.

Alguns estudos apontam que muitos professores de música encontram dificuldades em manifestar verbalmente seus conhecimentos sobre expressividade musical. Essa pode ser uma das razões pelas quais as estratégias não verbais, como modelagem aural e imitação, terem alguma popularidade (EBIE, 2004; JUSLIN; PERSSON, 2002; WOODY, 2006). EBIE (2004), ao estudar a habilidade de meninos e meninas em expressar, através do canto, emoções de felicidade, tristeza, raiva e medo, conclui que modelagem aural e aprendizado audiovisual são metodologicamente mais eficientes que instrução verbal e exploração cinestésica. LISBOA et al. (2005) mostram que estudantes de violino em níveis avançados são capazes de imitar, com consistência, aspectos expressivos do Adágio da Sonata para Violino Solo em Sol Menor de J. S. Bach tendo como modelo de referência uma gravação comercial. Estes autores demonstram, também, que o processo imitativo influenciou, mesmo que individualmente, a interpretação expressiva dos violinistas estudados.

Embora a apresentação de um modelo musical aos estudantes seja uma estratégia útil, alguns autores apontam restrições à imitação como estratégia de ensino de instrumento musical (JUSLIN et al., 2006). Em outras palavras, a imitação tem uma tendência ao conservadorismo. Outras limitações da modelagem aural e da imitação como estratégias de ensino de música residem na dificuldade de o estudante saber, 
ZORZAL, Ricieri Carlini. (2016) Propostas para o ensino e a pesquisa em cursos de graduação em instrumento musical: bases para uma reformulação do bacharelado. Per Musi. Ed. por Fausto Borém, Eduardo Rosse e Débora Borburema. Belo Horizonte: UFMG, n.34, p.62-88.

exatamente, o que ouvir e como representá-lo conforme suas habilidades específicas (LEHMANN, 1997).

Outras formas de estratégias não verbais de ensino instrumento musical são consideradas igualmente importantes no ensino da expressividade musical (KURKUL, 2007; MUNÕZ, 2007). KURKUL (2007), ao estudar aulas tutorias nos mais variados instrumentos, identifica que a habilidade de o professor sentir a resposta do aluno a suas estratégias não verbais de ensino é positivamente correlacionada com a efetividade da aula na percepção do estudante. Segundo o autor:

\begin{abstract}
O sentimento das pessoas serem bem ou mal entendidas parece estar relacionado mais as suas percepções do comportamento não verbal que do comportamento verbal de seus parceiros (...) Pesquisadores têm defendido há algum tempo (...) que a maioria do significado, especialmente do significado emocional, em qualquer situação social é derivado de marcas não verbais em vez de marcas verbais (Cahn e Frey citados por KURKUL, 2007, p.332).
\end{abstract}

Desse modo, o toque físico, estratégia comum em aulas de instrumento musical para assuntos relacionados à postura, relaxamento e digitação, deve ser conscientemente adaptado pelo professor à sensitividade do aluno. Os gestos, tanto faciais quanto corporais, que podem assumir o sentido de aprovação ou de reprovação, a distância que o professor fica em relação ao aluno, e até mesmo o silêncio, são estratégias não verbais que podem ser utilizadas eficazmente se o professor observar a resposta do aluno em relação a cada uma delas.

MUNÕZ (2007) defende que, para um efetivo ensino da expressividade musical, é necessário tornar o estudante de instrumento consciente de seus gestos durante a performance. Essa necessidade é confirmada por estudos que revelam que há uma relação positiva entre a intensidade da expressão musical e o tamanho do movimento gestual do intérprete. PALMER (2013), em uma profunda revisão sobre estudos de coordenação e movimento na performance musical, aponta que sinais visuais são tão efetivos quanto sinais auditivos na transmissão das intenções expressivas para a plateia. Em outras palavras, o movimento do performer torna-se gestualmente mais 
ZORZAL, Ricieri Carlini. (2016) Propostas para o ensino e a pesquisa em cursos de graduação em instrumento musical: bases para uma reformulação do bacharelado. Per Musi. Ed. por Fausto Borém, Eduardo Rosse e Débora Borburema. Belo Horizonte: UFMG, n.34, p.62-88.

acentuado quando as intenções expressivas da música tornam-se mais exageradas (KOKOTSAKI, 2003).

DAVIDSON (1993) traz um estudo no qual uma performance é apresentada de três maneiras diferentes a um grupo de observadores. Na primeira apresentação, o grupo de observadores pode ver a performance, mas sem acesso ao áudio. Na segunda apresentação, esse grupo pode ouvir a performance, mas sem acesso ao vídeo. $\mathrm{Na}$ terceira e última apresentação, o grupo pode ver e ouvir a performance. Os resultados desse estudo sugerem que o gestual do intérprete deve ser considerado tanto quanto a informação sonora na percepção musical. Nessa mesma linha, CHAIB, CHAIB FILHO e CATALÃO (2015a; 2015b) mostram, por meio de um estudo experimental sobre o gestual de uma performance percussiva, que as sensações de continuidade, suspensão e conclusão de um trecho musical são percebidas pelo ouvinte, com algumas variações na intensidade, através do movimento corporal do intérprete. DAVIDSON e CORREIA (2001) afirmam que os intérpretes não constroem simplesmente uma interpretação da obra com base no refinamento das habilidades motoras, eles utilizam o período de ensaio para conectar a experiência física, ou gestual, ao significado musical. DAVIDSON (2007) mostra, a partir de um estudo de caso de um pianista, que os movimentos expressivos usados pelo intérprete têm alguma consistência ao longo da execução. Assim, é possível afirmar que:

\footnotetext{
As estratégias básicas para ensinar estudantes a sentir, divertir, produzir e convencer com gestos expressivos são usualmente iniciálos na imitação de gestos para desenvolver suas próprias inspirações em seus movimentos futuros (MUNÕZ, 2007, p.59).
}

Dessa forma, o feedback audiovisual, tal como visualizações da prática em frente a um espelho, toques no corpo do aluno e informações verbais são estratégias essenciais para guiar o estudante de instrumento a uma sintonia entre seu gestual e a música que está praticando. 0 contato visual também se configura como uma importante estratégia não verbal de ensino. WILLIAMON e DAVIDSON (2002) mostram, estudando performances em duetos, a importância do contato visual na transmissão de ideias e intenções musicais. YARBROUGH (1975) considera que os altos níveis de contato visual e o uso de expressões faciais e corporais estão correlacionados ao aumento da 
ZORZAL, Ricieri Carlini. (2016) Propostas para o ensino e a pesquisa em cursos de graduação em instrumento musical: bases para uma reformulação do bacharelado. Per Musi. Ed. por Fausto Borém, Eduardo Rosse e Débora Borburema. Belo Horizonte: UFMG, n.34, p.62-88.

qualidade da performance em grupo. PALMER (2013) concorda ao indicar que um aumento na troca de olhar em rallentandos é crítico para o sucesso do controle temporal na performance em grupo. KURKUL (2007) nota que o contato visual foi o comportamento não verbal mais frequente em aulas individuais de instrumento musical.

\begin{abstract}
As interações visuais tornam-se possíveis através da mudança de sinais visuais que precisam ser codificados e decodificados a partir de uma perspectiva interpretacional comum entre participantes, para que um tipo de comunicação efetiva e estável possa ocorrer (KOKOTSAKI, 2003, p.170).
\end{abstract}

As estratégias para o ensino da expressividade musical baseadas em feedback computacional ainda encontram resistência entre professores e estudantes de música. Em um estudo com 135 estudantes de três países europeus, LINDSTRON et al. (2003) percebem que o ceticismo associado aos aplicativos computacionais no ensino da expressividade na música reside em questões como: a expressividade vem da alma; como o computador pode saber alguma coisa sobre emoção?

JUSLIN et al. (2006) elaboram uma plataforma computacional para auxiliar no ensino da expressividade musical. Apesar da confirmação empírica da efetividade da plataforma, os autores detectam, através da aplicação de questionários aos trinta e seis músicos que participaram da pesquisa, uma atitude negativa em relação ao uso de computadores para aprender expressividade. HENRY (2014), ao investigar a satisfação de cantores em relação ao uso do computador na avaliação da leitura a primeira vista, indica a mesma atitude negativa.

Estratégias baseadas em feedback computacional, assim como estratégias com o uso de recursos audiovisuais, precisam ser melhor aceitas no ensino de instrumento musical. Essa aceitação é necessária porque tanto é possível medir com objetividade as variáveis que regem a expressividade na performance musical, quanto é possível ensinar expressividade por meio dessas variáveis objetivas (JUSLIN et al., 2006). 0 Journal of Music, Technology and Education traz uma série de estudos que propõem a inserção da tecnologia na aula de instrumento musical. 


\section{1 - Uma contribuição qualitativa para o ensino e a pesquisa em instrumento musical}

Neste tópico são propostas definições e usos para as estratégias de ensino de instrumento musical. Como sugere ÁLVARES (2005, p.446), o relacionamento entre professor e aluno de instrumento musical ocorre através de palavras, gestos e sons. Dentro dessa perspectiva, a discussão aqui apresentada é iniciada com uma sugestão de categorização das estratégias de ensino que podem ser relacionadas ao uso das palavras. Posteriormente, são discutidas as estratégias de ensino empregadas no âmbito dos gestos e sons não verbais.

\subsection{1 - Estratégias verbais de ensino}

Uma proposta de categorização das estratégias verbais de ensino de instrumento musical, ou seja, aquelas voltadas para o uso das palavras, pode indicar três categorias: estratégias de ensino com o uso da linguagem figurada; estratégias de ensino com o uso da terminologia musical; e estratégias de ensino com o uso da linguagem literal. A linguagem figurada no ensino de instrumento propõe uma relação entre algo musical com algo não musical, como nos casos da metáfora e da similaridade, ou uma relação entre uma técnica de execução de determinado instrumento musical com uma sonoridade obtida por outro instrumento musical, como acontece na analogia. Sugerese que uma metáfora no ensino de instrumento musical é identificada quando há uma aproximação subjetiva onde se pode encontrar maiores ou menores semelhanças conceituais, como no exemplo a seguir: "pense no fluxo da música como um rio de águas calmas". Analogias são formas mais estruturadas do que as metáforas, ou seja, são níveis intermediários entre a imaginação pura e o pensamento lógico. Um exemplo de analogia pode ocorrer quando um professor de violão diz ao seu aluno: "imagine a arcada de um violinista executando essa frase". A similaridade pode ser considerada uma abreviação da metáfora, uma comparação mais pontual, tal como: "sua mão deve ter a forma de uma concha". 
As estratégias de ensino de instrumento musical com o uso da terminologia musical são aquelas que empregam os termos que são próprios da linguagem da música. São exemplos desses termos: forte, piano, rallentando, ritardando, ritenuto, crescendo, decrescendo, dolce, metálico, andante, presto, entre outros. A terminologia musical pode apresentar, em seu primeiro contato, um vocabulário extremamente novo ao aluno de instrumento. Por isso, é interessante que o aluno entre em contato com a terminologia própria da área, ainda que de forma paulatina, desde o início de seus estudos. Esse contato deve ser orientado para que esse aluno crie seus próprios mecanismos de obtenção dos recursos musicais relacionados a cada termo.

As estratégias de ensino de instrumento musical com o uso da linguagem literal são aquelas que empregam denotativamente a linguagem verbal. Assim, são incluídas nesse contexto toda fala proferida pelo professor que não pretenda criar relações figuradas nem contenha quaisquer terminologias musicais. Essa estratégia configurase como uma terceira possibilidade de estratégia verbal para a prática e o ensino da expressividade musical, ao lado da linguagem figurada e da linguagem técnica (JUSLIN; SLOBODA, 2001). São exemplos do uso da linguagem literal: conversas informais com a deliberada intenção de descontrair o ambiente; questionamentos biográficos sobre algum compositor ou instrumentista; indicações com o uso dos parâmetros físicos do som, tais como intensidade, altura, duração e timbre; sugestões para a estruturação da prática instrumental; entre outras. 0 emprego da linguagem literal no ensino de uma expressão artística pode parecer, num primeiro momento, pouco eficaz. Mas a objetividade, quando conscientemente aplicada no ensino de instrumento musical, pode oferecer aos alunos caminhos claros e algumas respostas que eles tanto precisam no momento em que se enveredam no pantanoso terreno da interpretação de um novo repertório.

\subsection{2 - Estratégias não verbais de ensino voltadas para o uso dos gestos}


De maneira geral, as estratégias não verbais de ensino de instrumento musical podem ser divididas em duas principais categorias: estratégias voltadas para o uso dos gestos; e estratégias voltadas para o uso dos sons. 0 uso dos gestos no ensino da música ocorre quase que ininterruptamente ao longo de uma aula de instrumento. E as estratégias de ensino que empregam gestos podem acontecer por meio de gestos musicais, marcações na partitura, contatos visuais, toques físicos, mudanças ou permanência da relação de proximidade entre professor e aluno, expressões faciais e, até mesmo, pelo silêncio.

Os gestos musicais, ou gestos de regência, são os movimentos de braços e mãos que o professor utiliza para sublinhar fraseados, indicações de timbres, dinâmicas e agógicas da peça. 0 emprego dos gestos musicais como estratégia de ensino faz com que seja possível uma conexão entre a experiência física do aluno e o significado musical de sua performance (MUNÕZ, 2007). Em outras palavras, é importante que o professor estimule o aluno a interiorizar essa experiência física para que ela seja coerente com a performance musical desejada.

As marcações na partitura configuram-se quando o professor utiliza a partitura para chamar a atenção do aluno. Essas marcações podem ser feitas com apontamentos sem o uso da escrita ou com o uso do lápis ou caneta esferográfica para sublinhar, destacar ou fazer quaisquer observações escritas na partitura. Os apontamentos feitos pelo professor canalizam a atenção do aluno e podem, inclusive, orientar seus estudos por algum tempo. Nesse sentido, o professor deve estar convicto que tais anotações são realmente as melhores orientações para aquela situação de ensino.

De acordo com YARBROUGH (1975; 1995), o contato visual configura-se quando o professor fixa sua atenção visual no aluno por, no mínimo, três segundos. Esse tempo foi estipulado por meio da observação comportamental, pois esta autora considera que o trabalho do aluno é passível de influência dessa estratégia somente a partir desse intervalo. Independente da duração desse contato, ele é significativo quando o professor focaliza sua atenção em questões pontuais e perceptíveis pelo aluno. Por isso, 
ZORZAL, Ricieri Carlini. (2016) Propostas para o ensino e a pesquisa em cursos de graduação em instrumento musical: bases para uma reformulação do bacharelado. Per Musi. Ed. por Fausto Borém, Eduardo Rosse e Débora Borburema. Belo Horizonte: UFMG, n.34, p.62-88.

é interessante que o contato visual seja explícito e acompanhado de uma leve inclinação corpórea.

0 toque físico configura-se quando o professor toca em qualquer parte do corpo do aluno. Essa estratégia pode depender do grau de intimidade estabelecido entre ambos. Portanto, o toque físico deve ser conscientemente adaptado pelo professor considerando a sensitividade do aluno em relação a essa estratégia não verbal.

A relação de proximidade entre professor e aluno, ao longo de uma aula de instrumento musical, pode fornecer uma diversidade de informações sobre os processos de ensino e aprendizagem envolvidos. Dessa forma, o professor que se coloca muito próximo de um aluno pode mostrar tanto um alto grau de intimidade, quanto um elevado poder intimidatório. Por outro lado, um professor que caminha a esmo durante a performance do aluno pode passar um sentimento de inquietação, ou mesmo de reprovação pelo que está sendo ouvido. Assim como no toque físico, essa estratégia deve ser adaptada à sensitividade do aluno para sua utilização eficaz.

As expressões faciais exprimem-se como estratégias de ensino quando a face do professor reflete contrastes entre aprovação e desaprovação da performance do aluno (YARBROUGH, 1995). Sorrir, levantar as sobrancelhas, arregalar ou fechar bem os olhos, franzir o sobrolho e apertar os lábios são exemplos de manifestação dessa estratégia. Muitas vezes esses contrastes são inconscientes e podem passar despercebidos, mas a naturalidade com a qual as expressões faciais ocorrem não diminui seu valor como estratégia não verbal de ensino. 0 aluno pode, ainda que inconscientemente, responder a cada um desses contrastes e orientar sua performance para obter o resultado desejado pelo professor.

O silêncio pode ser entendido como a ausência de percepção de outras estratégias de ensino. Não obstante, ele é também uma importante estratégia (KURKUL, 2007). Dessa forma, o silêncio pode ser considerado como um momento de reflexão e elaboração dos próximos passos a serem dados na aula. Esse momento pode criar no aluno uma tensão 
ZORZAL, Ricieri Carlini. (2016) Propostas para o ensino e a pesquisa em cursos de graduação em instrumento musical: bases para uma reformulação do bacharelado. Per Musi. Ed. por Fausto Borém, Eduardo Rosse e Débora Borburema. Belo Horizonte: UFMG, n.34, p.62-88.

e, consequentemente, um aumento na atenção para o que está por vir. Porém, para que o silêncio seja eficaz, ele deve ser percebido pelo aluno de forma a influenciar sua percepção da aula.

\subsection{3 - Estratégias não verbais de ensino voltadas para o uso dos sons}

As estratégias não verbais de ensino de instrumento musical são complementadas pelas estratégias voltadas para o uso dos sons. Essas estratégias são muito empregadas durante as aulas de instrumento e podem diferir por meio de sua fonte de emissão sonora. Assim, estão nesta categoria a demonstração instrumental, de fonte de emissão instrumental e a demonstração vocal e as onomatopeias, de fonte de emissão vocal.

A demonstração instrumental configura-se quando o professor utiliza o instrumento para demonstrar ou exemplificar suas intenções musicais ou imitativas. Nessas condições, a performance demonstrativa do professor pode assumir uma concepção expressiva ou intencionalmente não expressiva. Em outras palavras, essa estratégia pode ser empregada para oferecer um feedback positivo ou um feedback negativo sobre a performance realizada. Então, para que essa estratégia seja eficaz, é necessário que o professor faça uma distinção clara das duas situações para o aluno. Ou seja, o professor deve corroborar verbalmente quando a sua demonstração instrumental tem valor expressivo ou quando sua performance é intencionalmente não expressiva.

A demonstração vocal configura-se quando o professor utiliza a voz para solfejar, expressivamente ou não, melodias ou ritmos. As características apresentadas pela demonstração vocal como estratégia de ensino são semelhantes às características apresentadas pela demonstração instrumental, diferenciando-se apenas por sua fonte de emissão sonora.

A onomatopeia é, conforme sua definição das figuras semânticas, a imitação de um som com um fonema ou uma palavra. A colocação dessa figura de linguagem no campo das estratégias não verbais pode levantar algum questionamento. Todavia, defende-se que 
ZORZAL, Ricieri Carlini. (2016) Propostas para o ensino e a pesquisa em cursos de graduação em instrumento musical: bases para uma reformulação do bacharelado. Per Musi. Ed. por Fausto Borém, Eduardo Rosse e Débora Borburema. Belo Horizonte: UFMG, n.34, p.62-88.

as onomatopeias empregadas no ensino da música fazem mais referências ao universo não verbal da comunicação entre professor e aluno. Comparar um acelerando musical com a partida de um trem, o pulso de uma música com o "tic-tac" de um relógio, ou uma dinâmica piano com uma leve brisa, são alguns exemplos comuns de onomatopeias em uma aula de instrumento. Assim como nas demais formas de comunicação da linguagem figurativa, a onomatopeia deve criar relações em perfeita sintonia com o contexto sociocultural do aluno.

\section{2 - Uma contribuição quali-quantitativa para o ensino e a pesquisa em instrumento musical}

A proposta de categorização e as orientações para o uso das estratégias verbais e não verbais de ensino podem oferecer um panorama das narrativas que ocorrem em uma aula de instrumento musical. Além disso, reconhece-se que variam as condições nas quais as estratégias se apresentam. Enquanto uma aula pode estar centrada em estratégias verbais, outra pode enfatizar o uso de estratégias não verbais e assim por diante. Dessa forma, torna-se imprescindível a análise da magnitude e dos aspectos quantitativos dos eventos que ocorrem numa aula de instrumento musical.

Pelo exposto, como ponderam KARLSSON e JUSLIN (2008, p.311), entende-se que um entendimento do ensino instrumental requer micro-análises que usem métodos com abordagens quantitativas e qualitativas. Isto ocorre porque as interações do mundo real contêm muitas informações para serem reduzidas a poucas medidas quantitativas. Nesse sentido, métodos qualitativos trazem uma ênfase nas qualidades dos processos e significados em arranjos naturais. Por exemplo, muitas das interações sociais ocorrem por meio de conversação, o que exige que se considere o contexto social e o significado subjetivo durante a análise de dados. Por outro lado, medidas quantitativas podem ser úteis para descrever efetivamente aspectos estruturais do processo de ensino (ex. tempo efetivamente destinado a cada atividade).

Em outras palavras, após serem identificadas, as estratégias podem ser analisadas conforme sua magnitude. A análise da magnitude das estratégias verbais concentra-se 
ZORZAL, Ricieri Carlini. (2016) Propostas para o ensino e a pesquisa em cursos de graduação em instrumento musical: bases para uma reformulação do bacharelado. Per Musi. Ed. por Fausto Borém, Eduardo Rosse e Débora Borburema. Belo Horizonte: UFMG, n.34, p.62-88.

no volume da voz do professor ou na sua forma de impostação vocal, seja ela mais suave ou mais impositiva. Esses aspectos podem ser estudados por meio de programas que analisam ondas sonoras.

A magnitude das estratégias não verbais de ensino determina a frequência e a intensidade com a qual cada estratégia é empregada durante as aulas de instrumento musical. Com essa análise, torna-se possível identificar quais estratégias não verbais de ensino foram empregadas poucas vezes, mas sempre com intensidade, quais foram empregadas muitas vezes de maneira bem discreta, ou mesmo quais poderiam passar despercebidas pelo aluno. Portanto, uma definição operacional da magnitude das estratégias não verbais de ensino ajuda na determinação do momento onde essas estratégias são empregadas, o que pode contribuir para a análise quantitativa de sua frequência de ocorrência, ou descreve algumas de suas características, o que coopera para um entendimento qualitativo de sua aplicação. Esses aspectos podem ser estudados por meio de gravações em áudio e vídeo para posterior análise por juízes independentes.

YARBROUGH $(1975 ; 1995)$ propõe uma tabela de magnitude das estratégias não verbais voltada para a observação da prática de regentes corais. Adaptou-se essa tabela para que a magnitude das estratégias não verbais voltadas para o uso dos gestos fosse entendida de maneira mais ampla. Frisa-se que a análise da magnitude das estratégias não verbais voltadas para o uso dos sons está associada às durações ou repetições de cada uma delas. Assim, a alta magnitude na utilização da demonstração instrumental e da demonstração vocal está associada à alta contagem temporal no uso dessas estratégias e a alta magnitude na utilização da onomatopeia está associada à alta frequência no uso dessa estratégia. A adaptação da tabela proposta por YARBROUGH (1975, p.138; 1995, p.91) está exposta na Figura 2. 
ZORZAL, Ricieri Carlini. (2016) Propostas para o ensino e a pesquisa em cursos de graduação em instrumento musical: bases para uma reformulação do bacharelado. Per Musi. Ed. por Fausto Borém, Eduardo Rosse e Débora Borburema. Belo Horizonte: UFMG, n.34, p.62-88.

\begin{tabular}{|c|c|c|}
\hline Estratégia de ensino & Magnitude alta & Magnitude baixa \\
\hline Gestos musicais & $\begin{array}{c}\text { Utiliza os braços e as mãos para } \\
\text { sublinhar o fraseado musical. Grande } \\
\text { amplitude e variedade de movimentos } \\
\text { na indicação de fraseado, dinâmicas e } \\
\text { outros. }\end{array}$ & $\begin{array}{l}\text { Pequena amplitude dos gestos } \\
\text { musicais. Padrões gestuais } \\
\text { restritos, que nunca variam. }\end{array}$ \\
\hline Marcações na partitura & $\begin{array}{l}\text { Destaca, com lápis ou caneta, locais } \\
\text { que exigem maior atenção ou opiniões } \\
\text { de execução diferentes. }\end{array}$ & $\begin{array}{l}\text { Aponta locais que exigem } \\
\text { maior atenção ou opiniões de } \\
\text { execução diferentes, mas sem } \\
\text { empregar marcações escritas. }\end{array}$ \\
\hline Contato visual & $\begin{array}{l}\text { Observa a performance do aluno } \\
\text { inclinando-se acentuadamente em sua } \\
\text { direção. Fala olhando para o aluno de } \\
\text { forma que este perceba. }\end{array}$ & $\begin{array}{l}\text { Olha para o aluno } \\
\text { discretamente, ou olha para a } \\
\text { partitura ou para o teto. } \\
\text { Quando fala não olha para o } \\
\text { aluno. }\end{array}$ \\
\hline Toque & $\begin{array}{l}\text { O professor toca no corpo do aluno por } \\
\text { durações prolongadas. Em geral, vem } \\
\text { acompanhado por estratégias verbais, } \\
\text { para destacar questões como postura, } \\
\text { relaxamento, execução ou atenção. }\end{array}$ & $\begin{array}{l}\text { O professor não toca no corpo } \\
\text { do aluno ou toca apenas para } \\
\text { chamar sua atenção. Esses } \\
\text { toques têm durações curtas. }\end{array}$ \\
\hline $\begin{array}{l}\text { Relação de } \\
\text { proximidade }\end{array}$ & $\begin{array}{l}\text { Anda frequentemente e/ou senta-se } \\
\text { próximo ao aluno e costuma inclinar-se } \\
\text { acentuadamente em sua direção. }\end{array}$ & $\begin{array}{l}\text { Está sempre sentado e/ou } \\
\text { parado e pouco se inclina na } \\
\text { direção do aluno. }\end{array}$ \\
\hline Expressões faciais & $\begin{array}{c}\text { A face reflete grandes contrastes entre } \\
\text { aprovação e reprovação. Por exemplo, } \\
\text { sorrir, rir alto, levantar as } \\
\text { sobrancelhas, arregalar os olhos em } \\
\text { contraste com olhar carrancudo, } \\
\text { franzir o sobrolho, apertar os lábios e } \\
\text { fechar os olhos. }\end{array}$ & $\begin{array}{l}\text { Máscara neutra, sem mexer as } \\
\text { sobrancelhas e sem sorrir. }\end{array}$ \\
\hline Silêncio & $\begin{array}{l}\text { O silêncio pode vir acompanhado de } \\
\text { outras estratégias não verbais e é } \\
\text { utilizado após a fala ou a performance } \\
\text { do aluno ou entre outras estratégias } \\
\text { verbais. O silêncio se estabelece por } \\
\text { completo por alguns instantes. }\end{array}$ & $\begin{array}{l}\text { O silêncio ocorre apenas em } \\
\text { momentos em que o aluno está } \\
\text { falando ou tocando. Ou seja, o } \\
\text { silêncio nunca se estabelece } \\
\text { por completo. }\end{array}$ \\
\hline
\end{tabular}

Figura 2: Tabela de magnitude de estratégias não verbais de ensino voltadas para o uso dos gestos.

\section{3 - Considerações finais}

A realidade político-educacional vivida hodiernamente pelo Brasil impõe aos cursos de bacharelado em instrumento musical uma necessidade de reformulação que fuja da tradição conservatorial. Uma diversificação das atividades curriculares e extracurriculares desses cursos, com maior presença das atividades de ensino e pesquisa na formação discente, é um caminho viável. A partir da discussão apresentada, 
ZORZAL, Ricieri Carlini. (2016) Propostas para o ensino e a pesquisa em cursos de graduação em instrumento musical: bases para uma reformulação do bacharelado. Per Musi. Ed. por Fausto Borém, Eduardo Rosse e Débora Borburema. Belo Horizonte: UFMG, n.34, p.62-88.

propõe-se considerar a inclusão das disciplinas Pedagogia do Instrumento Musical e Pesquisa sobre o Ensino da Performance Musical na grade curricular dos bacharelados em instrumento musical.

A disciplina de Pedagogia do Instrumento Musical pode dar ensejo a uma profunda discussão sobre construtos, conceitos, definições e aplicabilidades das estratégias de ensino envolvidas na aquisição das habilidades de performance musical. Essa disciplina pode comportar questões sobre os espaços nos quais o ensino de instrumento musical ocorre, tais como bandas, conservatórios e festivais de música, e refletir sobre idiossincrasias dos formatos de ensino individual, coletivo e a distância. Além disso, como afirmam WEBER e GARBOSA, “outras oportunidades que podem ser oferecidas pelo curso consistem em espaços de experiência prática orientada, seja na forma de estágio ou em um tipo de laboratório pedagógico, no qual o bacharel possa experienciar a docência em cursos de extensão (2014, p.54)."

A disciplina de Pesquisa sobre o Ensino da Performance Musical pode trabalhar métodos e técnicas, tanto qualitativas quanto quantitativas, na observação dos diversos fenômenos presentes na aula de instrumento musical. Assim, os espaços e os formatos de ensino discutidos nessa disciplina podem ser delimitados a fim de proporcionar ao aluno a possibilidade de olhar o processo de ensino e aprendizagem da performance musical como objeto de pesquisa. Portanto, os preceitos aqui estabelecidos buscam vislumbrar um entendimento mais objetivo daquilo que, por hábito da tradição, pode ser considerado como algo que não pode ser submetido a um rigor acadêmico-metodológico. Como observa COUTO (2014):

$\mathrm{Na}$ prática musical acadêmica existem, por um lado, aqueles profissionais que defendem que o tipo de desenvolvimento não racional na prática musical seria inerente e legítimo a ela, e por outro lado, há aqueles que buscam conhecer racionalmente como o processo cognitivo musical funciona, na tentativa de desmistificar e democratizar essa prática. Essa dicotomia se torna mais aparente quando observamos os discursos desses dois grupos. Como é natural de se esperar em uma área que ainda está em fase de estruturação, não há um consenso sobre questões metodológicas e epistemológicas envolvidas na realização da pesquisa em Música, havendo entre seus atores até mesmo quem desacredite ou desmereça tal empreendimento. Em contrapartida, há o discurso daqueles que estão preocupados em assegurar que a subjetividade inerente a uma 

relação à produção de conhecimento tecido sobre ela (COUTO, 2014, p.244).

A partir dos argumentos aqui expostos, vê-se que o panorama atual mostra que dezenove universidades federais brasileiras oferecem algo em torno de novecentas vagas anuais para as diversas habilitações de bacharelado em música. Com isso, percebe-se a dimensão e os impactos do Decreto № 6.096/2007 sobre esses cursos. É preciso continuar discutindo propostas para que os bacharelados em instrumento musical continuem se adaptando ao contexto político-educacional vigente.

\section{Referências}

1. ÁLVARES, S. L. A. (2005). “Vertentes do saber musical: precedentes e consequentes epistemológicos rumo a uma fundamentação filosófica abrangente para uma educação musical contemporânea". In: ILARI, B. S. (Org.). Em busca da mente musical: Ensaios sobre os processos cognitivos em música - da percepção à produção. Curitiba: UFPR, p.429-452.

2. BARRY, N. H. e HALLAM, S. (2002). "Practice”. In: PARNCUTT, R. e MCPHERSON, G. E. (Eds.). The science and psychology of music performance: Creative strategies for teaching and learning. New York: Oxford University Press, p.151-166.

3. BARTEN, S. S. (1998). "Speaking of music: The use of motor-affective metaphors in music instruction". Journal of Aesthetic Education, v.32, p.89-97.

4. BURWELL, K. (2006). On musicians and singers. An investigation of different approaches taken by vocal and instrumental teachers in higher education. Music Education Research, v.8(3), p.331-347.

5. CERQUEIRA, D. L. (2013). "O curso de Bacharelado em Música da Universidade Federal do Maranhão: desafios de uma nova proposta". In: CONGRESSO DA ASSOCIAÇÃO NACIONAL DE PESQUISA E PÓS-GRADUAÇÃO EM MÚSICA, XXIII. Natal.

6. CERQUEIRA, D. L., ZORZAL, R. C. e ÁVILA, G. A. de. (2012). “Considerações sobre a aprendizagem da performance musical”. Per Musi, Belo Horizonte, n.26, p.94-109.

7. CHAIB, F., CHAIB FILHO, H. e CATALÃO, J. (2015a). “Gesto na performance da percussão, Parte 1: análise percentual de dados experimentais". Per Musi, Belo Horizonte, n.31, p.31-59.

8. CHAIB, F., CHAIB FILHO, H. e CATALÃO, J. (2015b). “Gesto na performance da 
ZORZAL, Ricieri Carlini. (2016) Propostas para o ensino e a pesquisa em cursos de graduação em instrumento musical: bases para uma reformulação do bacharelado. Per Musi. Ed. por Fausto Borém, Eduardo Rosse e Débora Borburema. Belo Horizonte: UFMG, n.34, p.62-88.

percussão, Parte 2: análise fatorial de correspondências de dados experimentais". Per Musi, Belo Horizonte, n.31, p.60-73.

9. COUTO, A. C. N. (2014). “Repensando o ensino de música universitário brasileiro: breve análise de uma trajetória de ganhos e perdas". Opus, Porto Alegre, v.20, n.1, p.233-256.

10. DAVIDSON, J. (1993)."Visual Perception of Performance Manner in the Movements of Solo Musicians". Psychology of Music, v.21, p.103-113.

11. DAVIDSON, J. (2007). "Qualitative insights into the use of expressive body movement in solo piano performance: a case study approach". Psychology of Music, v.35, p.381-401.

12. DAVIDSON, J. e CORREIA, J. S. (2001)."Meaning musical performance: A bodily experience". Research Studies in Music Education, v.17, p.70-83.

13. DUKE, R. A. e HENNINGER, J. C. (1998)."Effects of Verbal Corrections on Student Attitude and Performance". Journal of Research in Music Education, v.46(4), p.482495.

14. EBIE, B. D. (2004). "The effects of verbal, vocally modeled, kinesthetic, and audiovisual treatment conditions on male and female middle-school vocal music students' abilities to expressively sing melodies". Psychology of Music, v.32(4), p.405-417.

15. ELLIOTT, D. J. (1995). Music matters: a new philosophy of music education. Nova York: Oxford University Press.

16. GAUNT, H. (2008). "One-to-one tuition in a conservatoire: the perceptions of instrumental and vocal teachers". Psychology of Music, v.36(2), p.215-245.

17. HENRY, M. (2014). "Vocal Sight-Reading Assessment: Technological Advances, Student Perceptions, and Instructional Implications". Applications of Research in Music Education, v.33(1).

18. JUSLIN et al. (2006)."Play It Again With Feeling: Computer Feedback in Musical Communication of Emotions". Journal of Experimental Psychology: Applied. v.12, n.2, p.79-95.

19. JUSLIN, P. N. e PERSSON, R. S. (2002)."Emotional communication”. In: PARNCUTT, R. e MCPHERSON, G. E. (Eds.). The science and psychology of music performance: Creative strategies for teaching and learning. New York: Oxford University Press, p.219-236.

20. JUSLIN, P. N. e SLOBODA, J. A. (2001). Music and Emotion: Theory and Research. Oxford: Oxford University Press.

21. KARLSSON, J. e JUSLIN, P. N. (2008). "Musical expression: an observational study of instrumental teaching". Psychology of Music, v.36(3), p.309-334. 
ZORZAL, Ricieri Carlini. (2016) Propostas para o ensino e a pesquisa em cursos de graduação em instrumento musical: bases para uma reformulação do bacharelado. Per Musi. Ed. por Fausto Borém, Eduardo Rosse e Débora Borburema. Belo Horizonte: UFMG, n.34, p.62-88.

22. KOKOTSAKI, D. (2003). A grounded theory approach to understanding the pianist's perspective on the attainment of high quality in musical ensemble performance. Thesis (Doctor of Philosophy) - Department of Music, The University of Sheffield.

23. KURKUL, W. W. (2007). "Nonverbal communication in one-to-one music performance instruction”. Psychology of Music, v.35(2), p.327-362.

24. LEHMANN, A. C. (1997). "Acquired mental representations in music performance: Anecdotal and preliminary empirical evidence". In: HARALD, J. e LEHMANN, A. C. (Orgs.). Does practice make perfect? Current theory and research on instrumental music practice. Oslo: Norges Musiknhogskola, p.141-163.

25. LINDSTRON, E. et al. (2003). "Expressivity comes from within your soul": A questionnaire study of music students' perspectives on expressivity. Research Studies in Music Education, v.20, p.23-47.

26. LISBOA, T. et al. (2005). "Mastery through imitation: A preliminary study". Musicae Scientiae, v.9(1), p.75-110.

27. MUNÕZ, E. E. (2007). "When gesture sounds: Bodily significance in musical performance". In: WILLIAMON, A. e COIMBRA, D. (Orgs.) PROCEEDINGS OF THE INTERNATIONAL SYMPOSIUM ON PERFORMANCE SCIENCE. Porto: AEC, p.55-60.

28. PALMER, C. (2013). "Music Performance: Movement and Coordination". In: DEUSTCH, D. Psychology of Music. San Diego: Academic Press, p.405-422.

29. PEREIRA, M. V. M. (2014). "Licenciatura em música e habitus conservatorial: analisando o currículo”. Revista da ABEM, Londrina, v.22, n.32, p.90-103.

30. PERSSON, R. (1996). Brilliant performers as teachers: a case study of commonsense teaching in a conservatoire setting. International Journal of Music Education, v.28, p.25-36.

31. PHILPOTT, C. (2001). “Is music a language?” In: PHILPOTT, C.; PLUMMERIDGE, C. (Ed.) Issues in music teaching. London: Routledge, p.32-46.

32. SCARDUELI, F. e FIORINI, C. F. (2013). "Formação superior em violão: um diálogo entre programa de curso e atuação profissional”. Opus, Porto Alegre, v.19, n.1, p.215238.

33. SCHIPPERS, H. (2006). 'As if a little bird is sitting on your finger...': metaphor as a key instrument in training professional musicians. International Journal of Music Education, v.24(3), p.209-217.

34. SHELDON, D. A. (2004). "Listeners' Identification of Musical Expression through Figurative Language and Musical Terminology". Journal of Research in Music Education, v.52(4), p.357-368. 
ZORZAL, Ricieri Carlini. (2016) Propostas para o ensino e a pesquisa em cursos de graduação em instrumento musical: bases para uma reformulação do bacharelado. Per Musi. Ed. por Fausto Borém, Eduardo Rosse e Débora Borburema. Belo Horizonte: UFMG, n.34, p.62-88.

35. SKO0G, W. (2004). "Use of Image and Metaphor in Developing Vocal Technique in Choirs”. Music Educators Journal, v.90(5), p.43-48.

36. STOLLAK, M. A. e ALEXANDER, L. (1998). "The use of analogy in the rehearsal". Music Educators Journal, v.84(6), p.17-21.

37. SWANWICK, K. (2003). Ensinando música musicalmente. São Paulo: Moderna.

38. TOURINHO, A. C. G. S. e GURGEL, R. A. (2013). “Perspectivas de ingresso no mercado de trabalho por formados e recém-egressos de cursos de bacharelado em violão". Trânsito entre Fronteiras na Música. Belém: Universidade Federal do Pará.

39. WEBER, V. e GARBOSA, L. (2014). Ensaios sobre os saberes docentes do bacharel professor de instrumento. Música em Perspectiva, v.7, n.1, p.30-56.

40. WILLIAMON, A. e DAVIDSON, J. (2002). "Exploring Co-performer Communication”. Musicae Scientiae, v.1, p.53-72.

41. WOODY, R. H. (2001). "Eliciting expressive music performance: instructional approaches”. BIENNIAL MEETING OF SOCIETY FOR MUSIC PERCEPTION AND COGNITION. Kingston, Ontario, Canada.

42. WOODY, R. H. (2002). "Emotion, imagery and metaphor in the acquisition of musical performance skill”. Music Education Research, v.4(2), p.213-224.

43. WOODY, R. H. (2004). “Musicians' cognitive translation of imagery into properties of expressive performance". NATIONAL BIENNIAL CONVENTION OF MENC: THE NATIONAL ASSOCIATION FOR MUSIC EDUCATION, Minneapolis.

44. WOODY, R. H. (2006). "The Effect of Various Instructional Conditions on Expressive Music Performance". Journal of Research in Music Education, v.54(1), p.21-36.

45. YARBROUGH, C. (1975). "Effect of Magnitude of Conductor Behaviour on Students in Mixed Choruses". Journal of Research in Music Education, v.23, p.134-146.

46. YARBROUGH, C. (1995). "Investigação por observação”. In: KEMP, A. E. (Ed.). Introdução à Investigação em Educação Musical. Paris: Calouste Gulbenkian. p.87110.

47. ZORZAL, R. C. (2014). “Estratégias para o ensino de instrumento musical”. In: ZORZAL, R. C. e TOURINHO, A. C. G. S. (Orgs.). Aspectos práticos e teóricos para o ensino e aprendizagem da Performance Musical. São Luís: EDUFMA. p.12-45.

48. ZORZAL, R. C.; FERREIRA, A. N. A. (2016). “O ensino de música no Nordeste brasileiro: Notas históricas e desafios atuais". Revista Brasileira de História da Educação. In press. 
Nota sobre o autor

Ricieri Carlini Zorzal é bacharel em Violão pela Universidade Federal de Minas Gerais, mestre em Práticas Interpretativas pela Universidade Federal da Bahia e doutor em Educação Musical pela Universidade Federal da Bahia. É Professor Adjunto III da Universidade Federal do Maranhão, onde exerceu, entre 2012 e 2015, a função de chefe do Departamento de Artes. Coordenou, de 2010 a 2014, o Núcleo de Humanidades do Centro de Ciências Humanas (CCH) da UFMA, órgão deliberativo responsável pelas publicações científicas e pela organização de eventos acadêmicos do CCH-UFMA. Coordena o grupo ENSAIO (grupo de pesquisa em Ensino e Aprendizagem da Performance Musical), que tem projetos de pesquisa financiados pela FAPEMA e CNPq e tem publicado seus resultados em periódicos especializados e congressos no Brasil e no exterior. 